\title{
Людмила Кравцова
}

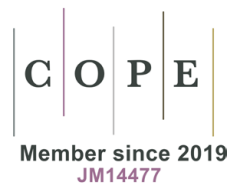

iD https://orcid.org/0000-0003-0143-003X

Каунасский технологический университет,

Факультет социальных, гуманитарных наук и искусств,

Каунас, Литовская республика ул. К. Донелайчио 73, 44249

liudmila.kravcova@ktu.lt

\section{Мир в зеркале Словаря моды}

\section{The world in the mirror of the Fashion Dictionary}

\section{Резюме}

В статье рассматривается вопрос о языке вестиментарной моды, ставшей сравнительно недавно объектом интереса лингвистов, занимающихся языком и дискурсом текстов о моде. Автор, в отличие от предыдущих лингвистических исследований, предлагает лингвокультурологический анализ лексикона моды. Цель исследования заключается в реконструкции определенного фрагмента картины мира, отраженного в Словаре моды, являющегося приложением к Электронной энциклопедии моды. Объектом исследования является группа слов со значением институтов моды. В результате исследования были выделены дифференциальные признаки, посредством которых можно описать устройство модного бизнеса. Автор на основе выделенных признаков приходит к выводу, что Словарь моды отражает социальную дифференциацию общества.

Ключевые слова: индустрия моды, картина мира, элитарная мода, вестиментарная мода, массовая мода, дифференциальные семантические признаки.

\section{Summary}

The article discusses the language of vestimentary fashion, which has recently become an object of interest for linguists studying the language and discourse of texts about fashion. The author offers a linguistic and cultural analysis of the fashion lexicon in contrast to previous linguistic studies. The purpose of the study was to reconstruct a certain fragment of the world picture of the Fashion Dictionary, which is an appendix to the Electronic Encyclopaedia of Fashion. The object of research is a group of words denoting fashion institutions. As a result of the study, differential features were identified by which the structure of the fashion business can be described. On the basis of the selected features, the author comes to the conclusion that the Fashion Dictionary reflects the social differentiation of society.

Keywords: fashion industry, the world picture, elite fashion, vestimentary fashion, mass fashion, differential semantic features. 


\section{ВВЕДЕНИЕ}

Американский социолог Г. Блумер еще в 1969 г. предлагал ученым обратиться к феномену моды, поскольку она имеет не периферийное значение, а напротив, простирает свое влияние на практически любую область человеческой жизни - стили искусства, медицину, промышленность и даже науку. Ограничивать ее сферой костюма - значит иметь очень неадекватное представление о ней (Блумер, 2008, 132). Позднее об этом же писал и российский социолог А.Б. Гофман:

Множество любопытнейших и сложнейших вопросов связано с модой. Но дело, конечно, не только в интересе, но и в важности и масштабностиэтого явления. Трудно назвать такую область социально-экономической икультурной жизни, где бы не сказывалось его влияние. И хотя влияниеэто осознается и признается далеко не всегда, оно не становится от этого менее значительны (Гофман, 1994, 165).

Мы не будем останавливаться подробно на философском и социологическом подходе к феномену моды - назовем лишь работы Р. Барта (2003) ${ }^{1}$, Блумера (1969), Ю. Кавамуры (2009) с тем, чтобы увидеть корреляцию между лингвистическим анализом лексикона моды и некоторыми социологическими теориями. Такая корреляция демонстрирует возможности междисциплинарного подхода к реконструкции того или иного фрагмента картины мира.

Обращаясь к столь популярной сегодня проблеме - исследованию феномена моды как лингвокультурного явления, мы, в первую очередь, будем говорить о «вестиментарной» моде, то есть в бартовском смысле - о «костюмной» моде, или, упрощая далее - о языке, которым пользуется мир модной одежды.

По сути всем тем, что помогает чувственному восприятию и общению между Душами, является Одежда, Костюм, который носят лишь сезон, а потом откладывают в сторону. Таким образом при должном рассмотрении оказывается, что уже в Одежде содержатся все мысли, мечтания, деяния и состояния человека, то есть весь внешний Мир, и все его содержание - это лишь Одежда, а суть всех наук лежит в философии Одежды, - писал в XIX британский философ и писатель Томас Карлейль (Свендсен, 2007, 7).

Эти слова взяты в качестве одного из эпиграфов к работе норвежского философа Л. Свендсена «Философия моды» (2007). В вестиментарной моде гораздо прозрачнее просматриваются функции моды, выделяемые социологами: 1) функция создания и поддержания единообразия и разнообразия в культурных образцах; 2) инновационная функция; 3) коммуникативная

\footnotetext{
${ }^{1}$ Впервые «Система моды» Р. Барта издана на французском языке в 1967 г.
} 
функция (Гофман, 1994). Первая функция вносит в общество необходимое для гармонизации ценностей согласие в отношении неких культурных образцов, при этом не приводя к конфронтации культурных установок, вторая заключается в передаче «модных» стандартов от одних людей к другим, а также в сообщениях индивида о принадлежности к определенной группе и своих ценностных установках. Третья функция необходима как средство подготовки общества к приему инноваций в целом: мода наиболее бескровно внедряет новые веяния. Наряду с тремя основными функциями отметим и такие функции, выделяемые Гофманом, как престижную и функцию психофизиологической разрядки, необходимой в монотонной жизни современного горожанина.

Нам представляется, что мир современной моды является наиболее гибким по отношению к принятию новизны, более того - вестиментарная мода коррелирует в смене образцов со скоростями нашего быстротекущего времени. И способствует этому иная теория моды - как экономического явления, служащего увеличению потребительского спроса и потому способного стимулировать быстрый приток капитала.

Современная модная индустрия представляет собой самостоятельный сектор экономики, включающий в себя производство и сбыт модных товаров (одежды, обуви, аксессуаров). Особенностями этого креативного сектора является крайний динамизм, быстрая скорость изменения всех процессов, жесткая конкуренция между модными брендами. ... Общий объем глобального рынка одежды - ключевого модного товара - в настоящее время, по данным MarketLine, составляет порядка 1,4 трлн долл. (почти 2\% мирового ВВП, согласно статистике МВФ). По прогнозам, в ближайшей перспективе рынок будет расти на 4-5\% в год (Седых, 2019, 2).

Мода, по Р. Барту, не может существовать без письма, ибо она не может иным способом распространяться, чтобы удовлетворить чисто экономические интересы производителей в промышленном обществе. Через сеть слов и создаваемых ими образов мода становится

вызывающей аппетит субстанцией... Желания вызывают не вещь, а ее имя... А раз так, то бесчисленные вещи, наполняющие и образующие воображаемое наших дней, оказываются все более в ведении семантики, и лингвистика, при некотором своем развитии, должна обрести второе рождение как наука о всех воображаемых мирах (Барт, 2003, 34).

Нельзя не отметить, что XXI век ознаменовался бурным ростом интереса к явлению моды не только среди социологов, но и среди лингвистов, в том числе - пишущих на русском языке (Долгова, 2014; Аракелова, 2014; Косицкая, 2014; Исхакова,2017; Одинцов, Одинцова, 2018; Матвеева, 2018 и др.), занимающихся как собственно языком, на котором говорит с нами «мода», так и анализом дискурса моды. 
Объектом данного исследования является мир моды, отраженный в соответствующих словарях, в нашем случае - в Словаре моды, являющемся приложением к электронной Энциклопедии моды (https://wiki.wildberries.ru/ glossary, 27.11.2020). Мы исходим из того, что «воображаемые миры» Барта в терминологии лингвистов можно приравнять к картине мира - модели действительности, то есть представлению о ее объектах и отношениях между ними, запечатленному в словаре народа. В той мере, в какой мода на данном этапе интернациональна (она рождается в Домах моды Лондона и Парижа, Милана и Москвы и т.д.), она пользуется не столько национальным языком, сколько неким «эсперанто» - языком, совмещающим слова из языков «отцов моды»: гайдлайн (англ.) и деним (фр.), муслин (итал.) и плюш (нем.). Вместе с тем значительная часть названий одежды и ее деталей существует на национальном языке (американская пройма, базовые вещчи, базовые цзвета, пиджак и др.), и словарь моды отражает это сплетение национального и заимствованного, демонстрирует специфику современного мира, глобализирующегося и одновременно сохраняющего национальные различия.

Избранное нами направление - выстраивание (реконструкция) фрагмента картины мира - соответствует духу современной лингвистики, пересекающейся с другими гуманитарными дисциплинами - философией, культурологией, психологией и т. д. Авторы названных нами выше лингвистических исследований, как нам представляется, идут собственно лингвистическим путем, не обращаясь к возможным корреляциям с социальными концепциями моды. Так, Т.В. Долгова (Долгова, 2014) рассматривает влияние глобализации на язык моды, в частности, влияние англицизмов на «модные» термины. Ф.Л. Косицкая, анализирует не лексикон моды, а дискурс каталогов моды и выделяет речевые жанры, представленные в дискурсе моды, например, «презентация модных тенденций сезона», «презентация модели/товара», «презентация модельера». Исследование О.С. Исхаковой носит диахронический характер - автор анализирует дискурс англоязычного модного журнала в аспекте речевых жанров и акцентирует внимание на изменении контента таких журналов - смене одних жанров другими и уменьшении доли вербального компонента за счет увеличения знаков иконического характера. Такой подход представляется нам весьма перспективным, поскольку отражает не только лингвопрагматические характеристики модного дискурса, но и изменение общественных предпочтений в области информации о мире моды.

Мы, в отличие от названных выше авторов, сосредоточиваем внимание на лексиконе, которым пользуется мода как индустрия - это позволяет на основе словаря понять структуру современного мира моды: коммерческие структуры, «живые эмблемы моды», духовных лидеров (Одинцов, Одинцова, 2018, 450) и в некоторой степени соединить лингвистический анализ с социологическими теориями моды - точнее, проиллюстрировать положе- 
ния о регулятивной функции моды, способах поддержания единых образцов в обществе, об особенностях коммуникации в этом фрагменте мира.

Модный - эпитет, который прикрепляется к тому или иному вестиментарному элементу определенными структурами, назначающими вещь или ее детали «модными». По словам американского социолога Ю. Кавамуры, создание одежды вовсе не означает, что она автоматически становится модной, а модельер, ее создавший, принимается обществом. Мода создается не отдельным индивидуумом, а командой специалистов, занятых в fashion-производстве, а потому мода - это результат коллективной деятельности (Кавамура, 2009, 13).

Избранный нами словарь-приложение к Электронной энциклопедии моды являет собой своеобразный вокабуляр моды - 241 слово, называющее актуалии определенного периода (основные разделы Энциклопедии обновляются ежегодно - мы анализируем данные 2020 г.). Такой словарь представляет собой гипертекст - за каждым словом стоит энциклопедическая статья, содержащая сведения о названных явлениях, например: Aльта Moдa (Alta Moda) - «итальянский вариант «Высокая мода» (https://wiki.wildberries.ru/ glossary, 27.11.2020). Подчеркнутые слова позволяют, кликнув на них, перейти к понятию высокая мода - «высший сегмент фэшн-рынка, высочайшее мастерство швейного искусства, эксклюзивные модели, производимые самыми знаменитыми дизайнерами и Модными домами» (там же). Нажатием клавиши мы можем перейти далее к статье фэшн-рынок и т. д. Некогда Р. Барт писал:

Мы собрали слова, дали им дефиниции - получается словарь. Мы собрали вещи (разумеется, обладающие именами), дали им описание - получается энциклопедия. Иногда, как в настоящем словаре, обе операции сочетаются вместе, получается словарь слов и вещей, энциклопедический словарь. $<\ldots>$ На словарной странице $<\ldots>$ перед нашим сознанием ...проходят сильнейшие проводники грезы: материки, люди, эпохи, орудия, всевозможные явления Природы и общества <..> Слово - словно корабль: поначалу оно кажется закрытым, плотно запертым в своей точно пригнанной арматуре; но очень легко оно само собой пускается в плавание, устремляется к другим словам, другим образам, другим желаниям... (выделено нами) (Барт, 2003, 500-502).

Отличие избранного нами словаря от большинства других словарей, включающих только названия одежды, в том, что он дает представление о значимых явлениях фэшн-бизнеса: Домах моды, кутюрье, мероприятиях моды (например, Лондонская неделя моды), то есть позволяет связать то, что Р. Барт называл «всевозможными явлениями Природы и общества».

Из 241 слова, представленного в в избранном нами словаре, 34 слова составляют две группы: а) существительные со значением лица, занятого в сфере модной индустрии и б) учреждения, организации, причастные к модному бизнесу. Именно в этих группах представлена константная часть 
«модного мира» - его организаторы. В рамках статьи мы рассмотрим одну из групп - учреждения, организации, причастные к модному бизнесу - и покажем возможности чтения словаря как гипертекста, рождающего картину мира моды, способную быть описанной в лингвистических терминах.

Назовем описанные в анализируемой Энциклопедии моды и указанные в ее Словаре учреждения и организации, причастные к процессу создания модной одежды:

1) Британский модный совет (BFC); 2) Совет модных дизайнеров Америки; 3) Синдикат Высокой моды; 4) ритейлер; 5) модельное агентство; 6) материнское агентство; 7) Дом моды.

Приведенный нами список слов при соответствующих операциях со словарной статьей демонстрирует иерархическую организацию моды: элитарную моду представляют Синдикат высокой моды, чей оффис находится в Париже - оказывается, получить звание кутюрье можно только будучи членом этого синдиката ${ }^{2}$. На первый взгляд может показаться, что соположенными Синдикату Высокой моды организациями является Британский модный совет и Совет модных дизайнеров Америки. Однако это не так, поскольку, как следует из определений (напр., «Совет модных дизайнеров Америки (The Council of Fashion Designers of America) - некоммерческая организация...»), обе организации являются некоммерческими, в то время как синдикат по определению есть коммерческое монопольное предприятие (Финансовый словарь. URL: http://www.finam.ru/dictionary/, 29.11.2020). Но эти организации могут быть соположены по другому признаку: защита интересов национальной моды ${ }^{3}$. Несмотря на то, что Синдикат высокой моды явлется межнациональной организацией, он все-таки отдает предпочтение национальным интересам в формировании моды - его членами, как было показано, могут быть только французские Модные дома, иностранцы входят в Синдикат на правах членов-корреспондентов (см. ссылку-2). Таким образом, мы можем выстроить оппозицию «коммерческие» - «некоммерческие» предприятия моды, члены которых объединятся по признаку «защита

${ }^{2}$ Синдикат Высокой моды (франц. Chambre Syndicale de la Couture Parisienne) - парижская организация, объединяющая Модные дома, создающие коллекции Haute Couture... В настоящее время называть себя кутюрье имеет право только член этой организации, который занимается изготовлением индивидуальных заказов (при этом использует не менее 70\% ручного труда); два раза в год представляет новые коллекции, которые состоят из 35 моделей одежды и демонстрируются манекенщицами; Членами Синдиката могут являться только парижские Модные дома. Иностранные компании и дизайнеры считаются членами-корреспондентами организации.

${ }^{3}$ Британский модный совет (англ. The British Fashion Council, BFC) - некоммерческая торговая группа модных дизайнеров Великобритании. Целью организации является продвижение британских модельеров во всем мире; Совет модных дизайнеров Америки (The Council of Fashion Designers of America) - Целью CFDA является привлечение внимания к модной индустрии,... признание модельеров как части американского искусства и культуры. 
национальных интересов». Синдикат высокой моды является объединением, к которому Модные дома и кутюрье относятся как часть к целому (гиперо-гипонимические отношения).

Таким образом, первый важный признак, по которому делятся слова и обозначаемые ими понятия, указывающий на организацию этой области жизни, это - коммерческая/некоммерческая направленность организаций (дифференциальный признак); общим признаком является национальная направленность. Отметим, что коммерческих организаций в области индустрии моды, согласно данным словаря, несравненно больше, чем некоммерческих; интересно также, что при общем межнациональном характере мировой моды определенные учреждения преследуют цель защиты национальной направленности в моде.

Признак 'коммерческий’ относится к Синдикату высокой моды, Дому моды, модельному агентству, материнскому агентству, ритейлеру. К некоммерческой группе обозначений соответствующих референтов относятся Совет модных дизайнеров Америки и Британский модный совет. При этом, как станет ясно из позднейшего изложения, Дом моды, модельные агентства, материнские агентства не характеризуются признаком 'национальная направленность'

Как определить характер деятельности (коммерческий/некоммерческий) описываемых учреждений, опираясь на дефиниции слов в анализируемом словаре, если в них не входят эти слова-маркеры? Энциклопедический словарь в той или иной форме содержит описание деятельности учреждения, из которого можно заключить о его коммерческой направленности, например: «Структуру Модного дома обычно составляют: главный дизайнер (арт-директор); модельеры; сотрудники, отвечающие за массовое производство; отделы продаж (маркетинговая служба, оптовое подразделение, бутики бренда)» (выделено нами). Наличие маркетинговой службы и бутиков говорит о том, что предприятие ориентировано на получение прибыли. Таким образом, мы можем отметить маркеры коммерческой деятельности: отдел продаж, бутики, маркетинг.

Из энциклопедических статей, касающихся их деятельности, становится очевидной элитарная направленность названных организаций. Слово элитарность не присутствует в дефинициях означенных словами понятий, но указание на то, что адресатами модных посланий являются обеспеченные слои, включение имен лиц, предпочитающих тот или иной Модный дом (например, от Валентино - Гвинет Пэлтроу, Дюженнифер Лопес, Софи Лорен, Джулия Робертс, Клаудия Шиффер), иногда упоминание цены вещи от того или иного кутюрье позволяют выстроить оппозицию элитарная - массовая мода. Об элитарности Совета модных дизайнеров Америки свидетельствуют, например, имена дизайнеров, входящих в него, и цены на товары, производимые ими: «Свадебные платья от Веры Вонг в свое время предпочли такие знаменитости, как Челси Клинтон, Иванка Трамп, Вероника 
Кэмпбелл-Браун, Виктория Бэкхем, Дженнифер Лопез... ». «Мода обладает респектабельностью; она несет в себе печать одобрения элиты - элиты, которая признана утонченной и считается мудрой в данной области устремлений» - писал Г. Блумер (Блумер, 2008, 135). В этой же энциклопедической статье указано, что платье прет-а-порте (для среднего класса) из коллекции Веры Вонг в среднем стоило 3,5 тыс. долларов.

Очевидно, что элитарная мода транслирует себя через одежду прет-апорте. «Прет-а-порте - готовая одежда, создаваемая известными модельерами для массового производства. Коллекции класса прет-а-порте служат основным источником доходов Модных домов. Все модели шьются в стандартных размерах, поскольку выпускаются для продажи в магазинах» - об этом свидетельствует Словарь моды при переходе к соответствующей статье. Таким образом, мы видим наличие еще одного признака, по которому дифференцируется мир моды: элитарная/высокая - массовая мода. Однако данную оппозицию точнее было бы представить как трехчленную. Поясним тезис. Демонстрировать высокую моду, согласно анализируемому словарю, призван Синдикат Высокой моды и входящие в него Дома моды. Средним членом оппозиции является Дом моды, который может выпускать одежду как очень высокого качества, следующую по рангу за «от-кутюр», так и одежду для массового потребителя, ориентирующегося на достаточно высокое качество. Об этом говорит слово бридж-бренд (товар, переходный между прет-а порте и масс-маркетом ${ }^{4}$, то есть одежда достаточно высокого качества средней ценовой категории). Итак, данные Словаря энциклопедии моды позволяют выстроить картину модного бизнеса, удовлетворяющего, согласно социологическим теориям, нашу потребность в психофизиологической разрядке и подготавливающим общество к принятию инноваций. В этой «картине мира» элементы распределены по оппозитивным признакам: высокая/элитарная мода (создается Синдикатом и включенными в него коммерческими структурами) - прет-а-порте (создается Домом моды - одежда может быть очень дорогой: как прет-а-порте люкс, так и массовая высокого качества) - масс-маркет. Говоря о масс-маркете как одежде для массового покупателя, мы можем обратиться к еще одному элементу модного бизнеса: ритейлеру. Ритейлер - компания, работающая с массовым покупателем, то есть значение этого слова характеризуется признаком «коммерческий» и «массовая мода». Словарь не предоставляет возможности перейти от данного слова к более широкому представлению об организации массовой моды. Вместе с тем в нем имеется статья демократичная марка: «Демократичные марки - бренды низшего сегмента фэшн-рынка, характеризующиеся де-

${ }^{4}$ Масc-ма́ркет (от англ. mass market - «массовый рынок») - продукция, рассчитанная на средний класс, на «массового потребителя». Отличается средним уровнем качества и демократичностью цен. Реализуется в специализированных магазинах. 
мократичными ценами, массовостью продукции, сравнительно невысоким качеством изделий». В этой статье названы и производители таких марок (напр., NewYorker, Bershka, Sasch - массовые бренды; Kiabi, Jennyfer, TATI, Sela - бюджетные бренды). Нужно сказать, что этот сегмент фэшн-рынка освещен в Словаре моды весьма слабо (слова бюджетные бренды, массовые бренды в нем отсутствуют, что затрудняет понимание различия между ними).

«Инструментом», поставляющим «средства» для трансляции моды, являются модельные агентства: модельное агентство - организация, представляющая моделей для работы в модной индустрии и рекламе. Модельное агентство - коммерческое предприятие, не связанное ни с творчеством в области моды, ни с производством товаров. С высокой модой модельное агентство может быть связано через mоn-моделей 5 . Модельное агентство имеет свои дочерние (рангом ниже) организации: материнские агентства, которые, как явствует уже из их названий можно рассмотреть на лингвистическом уровне как находящиеся в гиперо-гипонимических отношениях. Таким образом, можно выстроить еще одну оппозицию в мире моды: создатели модной одежды - трансляторы (одновременно могут быть продавцами) продавцы. Такая картина организации модной индустрии вырисовывается по данным Словаря моды. Члены представленной оппозиции также выступают семантическими маркерами, через которые могут быть описаны значения имен институтов моды: например, Синдикат высокой моды - 'создатель', 'коммерческий', 'защита национальной направленности', 'элитарная мода'.

Небезынтересно, что в Словарь не включено выражение уличная мода (street-Fashion), которая рассматривается в качестве альтернативы высокой моде. Ее начало видят в Токио, где молодежь пресытилась глянцем, или в послевоенном Лондоне, где снижение уровня жизни повлекло новое явление - стало модным чинить одежду или делать ее своими руками.

Уличная мода находит свое место сегодня даже на сайте весьма респектабельного журнала VOGUE, конкурируя со степенью представленности на разных сайтах с элитарной модой. Вместе с тем Словарь включает весьма популярное сегодня слово фейк, которое, в применении к моде, означает «подделку изделия известного модного бренда. Отличается низким качеством и невысокой ценой». Мистификация равенства, на наш взгляд, проявляется именно в популяризации фейк-изделий, порождающих, например, такие рекламные призывы: «Сумки фейк известных брендов! Отличное качество! Выкуп в сентябре.

5 Ton-модель - «высокооплачиваемая модель, имеющая контракты с ведущими брендами и регулярно появляющаяся на обложках глянцевых журналов. Термин появился в 60-х годах XX века) (Словарь моды). Материнское агентство - модельное агентство, с которым модель подписывает свой первый контракт. Оказывает модели помощь в поиске заказов, с которых имеет определенный процент, а при недостатке работы - в поиске более серьезного агентства» (Словарь моды). 


\section{ЗАКЛЮЧЕНИЕ}

Мы описали мир модной индустрии как лингвокультурологическое явление - через набор дифференциальных семантических признаков, выявленных на основе лексических оппозиций, и показали иерархию в организации модного бизнеса с использованием лингвистических инструментов. Можно сказать, что анализируемый словарь в исследуемом фрагменте картины мира демонстрирует социальную дифференциацию общества: обеспеченные слои ориентированы на элитарную моду, которая, проходя через производство и маркетинг, постепенно демократизируется. В свою очередь, существующая за пределами картины мира Словаря моды «уличная мода» бросает свой вызов подиумам и кутюрье.

\section{БИБЛИОГРАФИЯ}

Аракелова, А.Р. (2014). Дискурс моды как объект лингвистического моделирования. Филологические науки. Вопросы теории и практики. 10-2, 21-24.

Барт, Р. (2003). Предисловие к «Словарю Ашетт». В: Барт Р. Система моды. Статьи по семиотике моды. Москва: изд-во им. Сабашниковых.

Блумер, Г. (2008). Мода: от классовой дифференциации к коллективному отбору. Bluтег H. Fashion: from class differentiation to collective selection // sociological quart. - Columbia, 1969. - Vol. 10, n 3. - P. 275-291. Социальные и гуманитарные науки. Отечественная и зарубежная литература. Серия 11: социология. 132-134.

Гофман, А.Б. (1994). Мода и люди. Новые теории модного поведения. Москва: Наука.

Долгова, Т.В. (2014). Влияние прочессов глобализаиии на формирование языка моды. Англиичизмы в профессии. В мире науки и искусства: вопросы филологии, искусствоведения и культурологии: сб. ст. по матер. XXXVI междунар. науч.-практ. конф. № 5(36). Новосибирск: СибА, 3-13.

Исхакова, О.С. (2017). Динамика развития письменно-речевых жанров журнального дискурса моды: на материале анализа англо-язычного журнала моды Harper's Bazaаr. Авт. дис. канд. фил. наук. Уфа.

Кавамура, Ю. (2009). Теория и практика создания моды. Минск: Гревцов Букс, Издательство Гревцова.

Косицкая Ф.Л. (2014). Дискурс моды и его жанровая дифференциащия. Вестник ТПГУ, 4(145), $22-26$.

Матвеева, Е.К. (2018) Языковая идентификация архетипических образов в русском рекламном дискурсе моды. Авт. дис. канд. фил. наук. Казань.

Одинцов, А.А., Одинцова, О.В. (2018). Об инструментах управления модой. Вестник РУДН, т. $5,4,446-457$.

Свендсен, Л. (2007). Философия моды. Москва: Прогресс-Традиция.

Седых, А.И. (2019). Индустрия моды. Москва-ВШЭ.

Словарь Энииклопедии моды. URL: https://wiki.wildberries.ru/glossary (доступ 12.12.2020).

Финансовый словарь. Финам. URL:. http://www.finam.ru/dictionary (доступ 22.11.2020). 


\section{$* * *$}

Arakelova, A.R. (2014). Diskurs mody kakob"ekt lingvisticheskogo modelirovaniya. Filologicheskie nauki. Voprosy teorii i praktiki. 10-2, 21-24.

Bart, R. (2003). Predislovie k «Slovaryu Ashett». V: Bart R. Sistema mody. Stat’i po semiotike mody. Moscow: izd-vo im. Sabashnikovykh.

Blumer, H. (2008). Fashion: from klass differentiation to collective selection/sociological quart. Social sciences and Humanities. Domestic and foreign literature. Series 11: Sociology, $132-134$.

Dolgova, T.V. (2014). Vliyanie protsessov globalizatsii na formirovanie yazyka mody. Anglitsizmy v professii. V mire nauki i iskusstva: voprosy filologii, iskusstvovedeniya i kul'turologii: sb. st. po mater. XXXVI mezhdunar. nauch.-prakt. konf. № 5(36). Novosibirsk: SibA, 3-13.

Finansovyi slovar'. Finam. URL: http://www.finam.ru/dictionary (dostup 22.11.2020).

Gofman, A.B. (1994). Moda i lyudi. Novye teorii modnogo povedeniya. Moscow: Nauka.

Iskhakova, O.S. (2017). Dinamika razvitiya pis'menno-rechevykh zhanrov zhurnal'nogo diskursa mody: na materiale analiza anglo-yazychnogo zhurnala mody Harper's Bazaar. Avt. dis. kand. fil. nauk. Ufa.

Kavamura, Yu. (2009). Teoriya i praktika sozdaniya mody. Minsk: Grevtsov Buks, Izdatel'stvo Grevtsova.

Kositskaya F.L. (2014). Diskurs mody i ego zhanrovaya differentsiatsiya. Vestnik TPGU, 4(145), $22-26$.

Matveeva, E.K. (2018) Yazykovaya identifikatsiya arkhetipicheskikh obrazov v russkom reklamnom diskurse mody. Avt. dis. kand. fil. nauk. Kazan.

Odintsov, A.A., Odintsova, O.V. (2018). Ob instrumentakh upravleniya modoi. Vestnik RUDN, t. 5 , $4,446-457$.

Sedykh, A.I. (2019). Industriya mody. Moscow-VShE.

Slovar'Entsiklopedii mody. URL: https://wiki.wildberries.ru/glossary (dostup 12.12.2020).

Svendsen, L. (2007). Filosofiya mody. Moscow: Progress-Traditsiya. 